\title{
Valor histórico y turístico de México
}

El análisis histórico que marca la trascendencia de la República Mexicana como nación, al emplear el método de análisis y síntesis documental que permite realizar consideraciones de hechos $y$ acontecimientos histórico-culturales, concluye que es necesario impulsar la industria turística, tomandocomo primicia el patrimonio histórico y cultural con que cuenta México, que posibilite generar empleos directos e indirectos.

Juana Patricia Muñoz Chávez / Victoria Hernández Ramírez / Héctor Barrios Quiroz

Universidad Autónoma del Estado de Hidalgo, México.

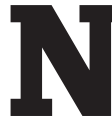

o son pocas las ocasiones en que el ramo turístico, principalmente en México, se ha desaprovechado diferentes elementos que podrían activar su completo potencial. Dentro de una economía que lo está pidiendo a gritos, incentivar la industria turística se ha vuelto una necesidad imperante ante la amenaza de la extinción de los mantos petroleros o la repatriación de los mexicanos de Estados Unidos, cuyas remesas constituyen la primera fuente de inyección de recursos económicos procedentes del extranjero.

Considerando los puntos anteriores, y sobre todo ante el temor de hacergrandes desembolsos e conóm i cos para invertir en complejos turísticos cuyas

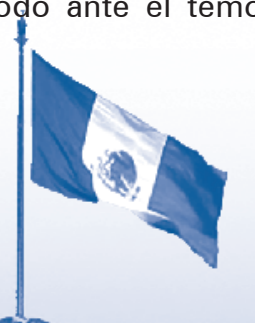

utilidades no estarían aseguradas, el sector público puede aprovechar el patrimonio histórico de México para el fomento turístico, tomando en cuenta que Chichen Itzá fue declarada maravilla del mundo moderno en 2007. Se constata el interés en todo el mundo en el aspecto cultural, ejemplos como Chichen Itzá, Teotihuacan, Tula, Uxmal y Palenque han sido considerados símbolos de la cultura mesoamericana, pero existen otros destinos que tienen un gran potencial $y$ han

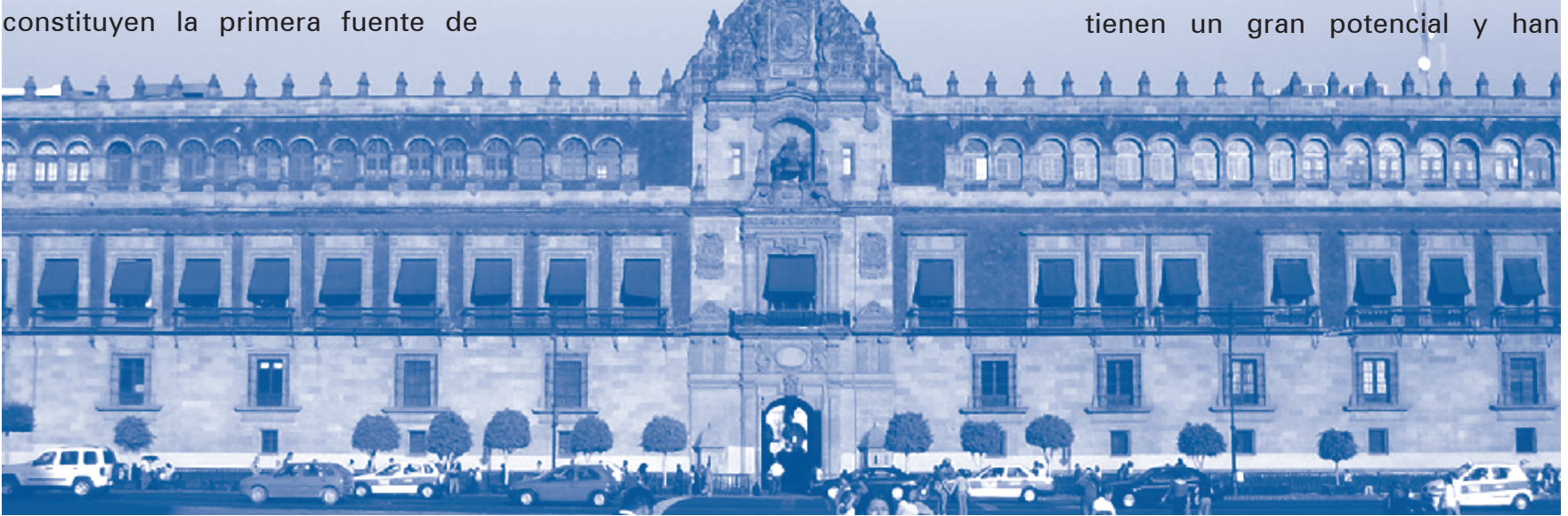




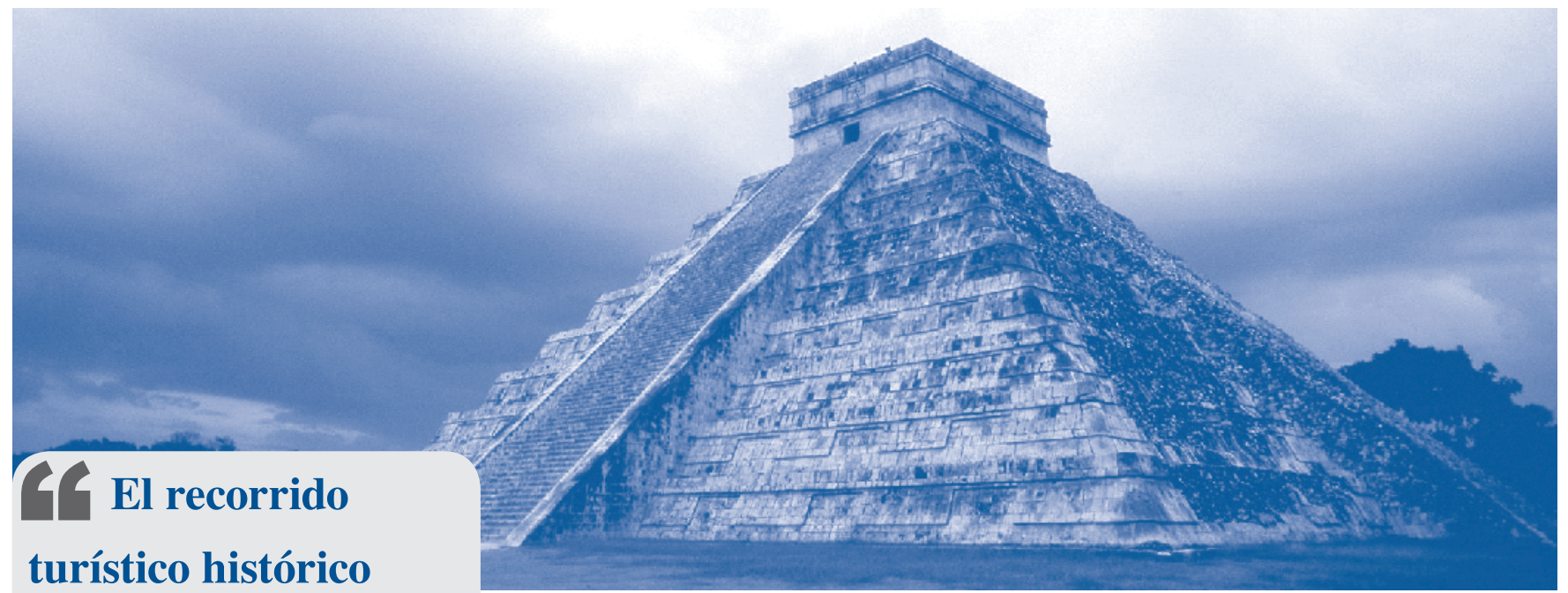

\section{puede ser}

\section{interminable. Sin}

\section{embargo, rara vez}

\section{es aprovechado y}

\section{en una economía}

\section{que pretende crecer}

ante una inevitable

extinción del petróleo.

\section{La historia y el}

\section{turismo juntos son la}

\section{llave del desarrollo.}

sido descuidados como Paquimé en Chihuahua, Itzamná en Yucatán e incluso Cuicuilco en la Ciudad de México, destinos que con un adecuado programa de publicidad y restauración serían destinos turísticos de alto impacto no solo a nivel nacional, sino internacional.

Sin embargo, no únicamente la Mesoamérica prehispánica representa una serie de destinos turísticos potencialmenteredituables al turismo de México. A lo largo de su historia se encuentran huellas imborrables de la construcción de la nación y que son puntos de referencia insoslayables. En la época colonial aparecen las primeras ciudades de la Nueva España: México, Puebla, Guanajuato, Veracruz, Valladolid (hoy Morelia) y Oaxaca, que representan actualmente bastiones de expresiones artísticas y culturales de la fusión de dos culturas. Tan solo en la Ciudad de México se encuentra ubicado el zócalo capitalino, que reúne a la Catedral Metropolitana y el Palacio Nacional en conjunto con el Templo Mayor. Este destino además es muy económico y representa un claro ejemplo de conquista social, espiritual y política por parte de la España colonialista sobre el pueblo azteca. Puebla, también conocido como el relicario de América, ofrece una gastronomía y arquitectura única. Taxco representa una muestra interesante de adaptación al medio ambiente de la Sierra de Guerrero, cuya iglesia (Santa Prisca) es un ícono del barroco churrigueresco de México. Guanajuato no solo como ciudad sino como Estado marca una etapa de transición entre el México Novohispano y el México independiente, considerado como cuna de la independencia. Se puede encontrar al pueblo de Dolores, Hidalgo, donde la madrugada del 16 de septiembre de 1810 se convocó a la lucha armada y ello representa un lugar clave (principalmente la parroquia de Dolores). Dentro de la capital del Estado se encuentra la Alhóndiga de Granaditas, que representa la última fortaleza de los españoles radicados en la ciudad ante el embate del ejército insurgente de Miguel Hidalgo y que al caer en manos de los libertadores hizo de Guanajuato, la primer plaza importante tomada por los insurgentes. Guanajuato además de presentar año con año el festival cervantino, emblema de la cultura iberoamericana, es el lugar donde inició el sueño de libertad de un pueblo sometido por 300 años al poderío de España.

La guerra de independencia da a Guadalajara el atractivo de ser la ciudad donde se declara el 6 de diciembre de 1810 la abolición de la 
esclavitud, cuando no se había hecho aún en ningún país de América, además de promoverse la primera Revolución Agraria que buscaba la reivindicación de los naturales en referencia a sus tierras ancestrales. Guadalajara no solo es la segunda ciudad en importancia del México actual, sino que representa la cuna de los primeros decretos más importantes de reivindicaciones sociales en México lo que la hace doblemente atractiva como destino turístico.

Cuautla, Morelos, cuyo nombre del Estado al que pertenece representa un homenaje a José María Morelos y Pavón, representa el lugar donde Morelos cobra fama como general del movimiento de independencia al llevar a cabo el famoso sitio el 24 de diciembre de 1811 y que lo va a etiquetar como un estratega de fama internacional que despertó la admiración del general Napoleón Bonaparte.
Otro destino interesante de México y que respira libertad es Iguala en el Estado de Guerrero, enclavada en la zona serrana del sur de México. Iguala representa la culminación de la independencia, el sueño libertario de toda una nación, la unión de todos los mexicanos, el emblema de las tres garantías: unión, religión e independencia que marcarían las pautas del México independiente y que darían lugar al nacimiento de la bandera nacional con los colores verde (independencia), blanco (religión) y rojo (unión), que culminaría con el desfile del 27 de septiembre de 1821 en la Ciudad de México por la avenida de los Insurgentes que debe su nombre a este evento precisamente.

El periodo de guerra de independencia abarca once años de la historia del país. Inicia el 16 de septiembre de 1810 y culmina el 27 de septiembre de 1821.
Si se sigue una línea del tiempo de la Historia de México se encuentra la primera etapa del México independiente que representa graves problemas en el ámbito económico y político, a grado tal que en 1823 la región centroamericana decide separarse del país (Cosío 2002). Todas las naciones excepto Chiapas decide quedarse dentro del entonces Imperio Mexicano. Chiapas no es solo riqueza natural, representa identidad nacional, pero desgraciadamente es uno de los Estados más descuidados del gobierno federal no solo en el aspecto turístico, sino en el económico y social. De ese descuido se desprende el movimiento encabezado por el subcomandante Marcos del Ejército Zapatista de Liberación Nacional (EZLN), de lo cual se hace necesario mencionar que para el desarrollo del turismo es menester también apoyar a la comunidad, porque un desequilibrio socio-económico afecta la estabilidad, elemento

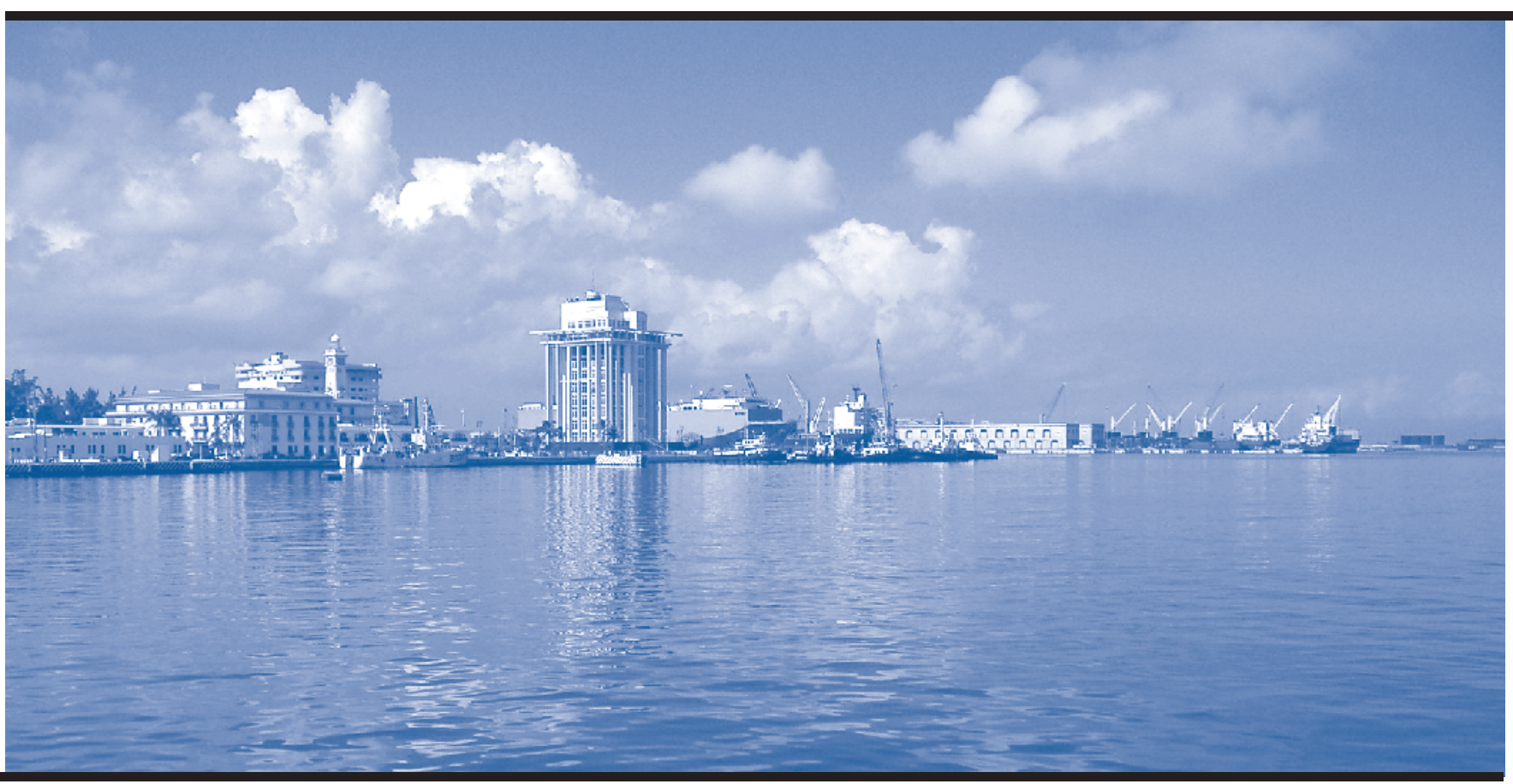


clave del turismo que permite dar seguridad al turista que a fin de cuentas es el mejor promotor $y$ publicista de los servicios turísticos.

Otro punto importante de México es el heroico puerto de Veracruz, que ha soportado varias invasiones por parte de potencias extranjeras como España, Francia, Inglaterra y Estados Unidos. Con este último país se libró una épica batalla en Cerro Gordo, que representó una férrea resistencia que desgraciadamente terminó en derrota y culminó con la invasión de la Ciudad de México en un sitio que representa para todos los mexicanos un bastión heroico: El Castillo de Chapultepec. Este verdadero monumento histórico hoy es sede del museo de Historia de México y en él se puede encontrar diversas salas que exhiben aspectos que hacen respirar los momentos más importantes de la historia de nuestro país, pero lo más importante es lo que el Castillo de Chapultepec representa en sí: fue sede del Colegio Militar del México independiente y en referencia a la guerra contra los Estados Unidos representa una de las epopeyas épicas más honrosas de la Historia de México, donde seis cadetes del colegio: Juan de la Barrera, Juan Escutia, Francisco Márquez, Fernando Montes de Oca, Vicente Suárez y Agustín Melgar junto con Nicolás Bravo y el Batallón Activo de San Blas a cargo de Santiago Xicotencatl defendieron su posición el 13 de septiembre de 1847 a grado tal que narran algunas crónicas de la época que el cadete Juan Escutia se envolvió en la bandera nacional y se aventó al vacío para evitar que el lábaro patrio cayera en manos de los invasores. Con la caída de México contra Estados Unidos en la guerra de 1846 a 1848, el país pierde más de la mitad de su territorio (Briceño 1999). La guerra entre México contra Estados Unidos tiene su antecedente inmediato en la independencia de Texas en 1836, en donde por los Tratados de Velasco se concede dicha emancipación con la condición de que Texas no se incorporase a territorio estadounidense, acuerdo que es violado en marzo de 1845 y representa una clara provocación a los intereses de México, ya que además los norteamericanos pretendían extender la frontera texana hasta el Río Bravo, siendo que desde los tiempos de la conquista esta frontera estaba en el Río Nueces al norte del Río Bravo lo que irremediablemente llevó a estas naciones a la guerra en 1846 .

La guerra inicia en California, con victorias del general norteamericano Taylor que repliega al ejército mexicano hasta Saltillo, mientras el general Scott es enviado a Veracruz. Santa Anna se incorpora a la lucha y repliega a Taylor hasta Buenavista, California, pero no se atreve a liquidarlo (22 y 23 de febrero de 1847) e inesperadamente deja escapar la victoria. El general Scott ataca Veracruz y Santa Anna. Después de su deshonrosa retirada decide combatirlo, pero es finalmente derrotado en Cerro Gordo y decide regresar a la capital. Scott se dirige al Castillo de Chapultepec en ese tiempo sede del Colegio Militar y lo ataca el 13 de septiembre de 1847, El colegio es defendido por Nicolás Bravo y los cadetes Juan Escutia, Juan de la Barrera, Fernando Montes de Oca, Francisco Márquez, Vicente Suárez y Agustín Melgar apoyados por el Batallón Activo de
En el México contemporáneo la década de los años 60 del siglo pasado, representa un cambio político-cultural importante que históricamente presenta a Tlatelolco como ícono de lucha y resistencia ante la represión gubernamental representada por los acontecimientos del 2 de octubre de 1968.

San Blas de Santiago Xicoténcatl, pero desgraciadamente caen y con ello se produce la inminente derrota en esta injusta guerra representada por el izamiento de la bandera norteamericana en el zócalo capitalino el 23 de septiembre de 1847. La guerra culmina el 2 de febrero de 1848 con la firma de los Tratados de Guadalupe-Hidalgo, donde México es obligado a ceder los territorios del sur del Río Nueces, Alta California y Nuevo México (que incluía los territorios de los actuales estados de Nevada y Arizona). Pierde más de la mitad de su territorio.

Posterior a la guerra logra, recuperar Yucatán, quien por problemas con el gobierno centralista decretó su independencia oficialmente en 1846 y por la famosa guerra de 
castas entre hacendados yucatecos e indígenas agudizó sus problemas internos hasta que en 1849 Yucatán decide solicitar nuevamente su anexión a México, de ahí se puede

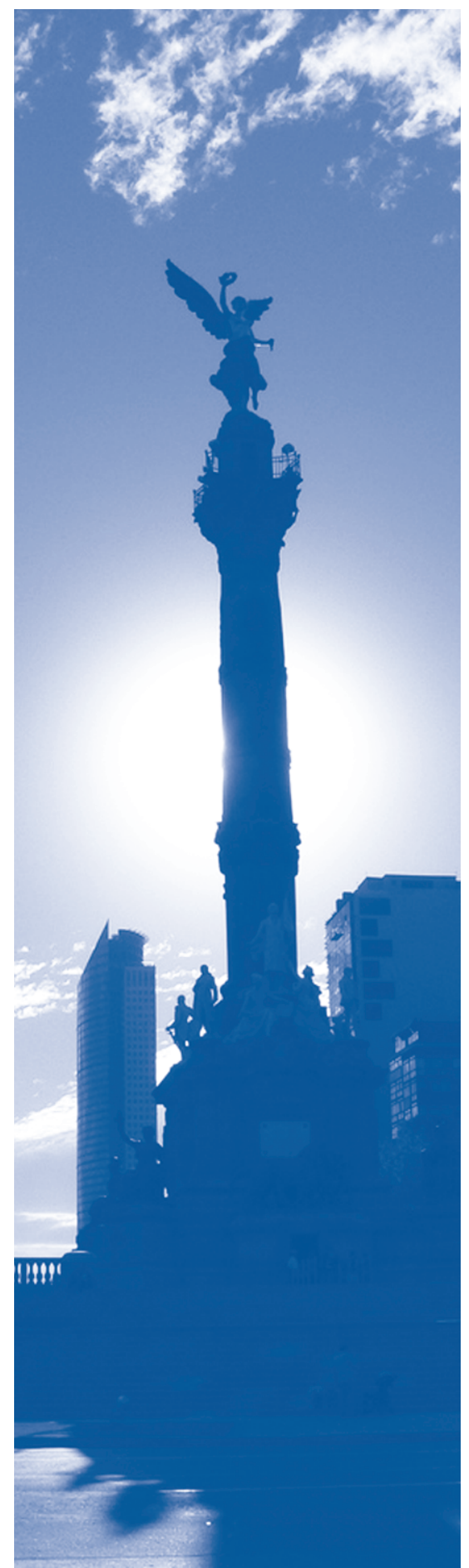

entender por qué en Yucatán la mayoría de sus habitantes no se sienten identificados como mexicanos, sino como "yucatecos". Si se visita el lugar y se pide una cerveza en cualquier local te preguntan: ¿desea cerveza nacional, cerveza yucateca, o importada? (refiriéndose a cualquier otra cerveza de otra región del país). Sin embargo, Yucatán es rico en gastronomía y es importante recordar que posee una de las siete maravillas del mundo moderno: Chichen Itzá, por lo que es básico impulsar el turismo en esta región alguna vez conocida como la “Hermana República de Yucatán”.

Con el avance de la historia se entra en una etapa de conflictos constantes que provocan la llegada al poder de su "Alteza serenísima": Antonio López de Santa Anna, que durante su dictadura crea el Gran Teatro de Santa Anna, obra cumbre de su despilfarro económico, pero que representa arquitectónicamente una verdadera obra de arte.

Para el año 1862, viene la intervención francesa (Delgado, 1992) y con ello la famosa batalla del 5 de mayo, que es conmemorada año con año no solamente en Puebla, sino también en la Ciudad de México, con representaciones que incluso han trascendido la frontera nacional. No se debe olvidar que la celebración de la batalla del 5 de mayo es más importante para la comunidad mexicana en Estados Unidos que el mismo 16 de septiembre, el que se conmemora el inicio de la independencia de México.

La intervención francesa tiene su causa inmediata en el año 1862. Ante la inminente crisis que atravesaba México, el presidente
Juárez declara una moratoria de dos años en relación con los pagos con los acreedores extranjeros, lo que sirvió de pretexto al ejército de Francia para invadir el país no sin antes producirse una batalla el 5 de mayo de 1862 en donde el ejército mexicano al mando del general Ignacio Zaragoza (que por cierto nació en Texas) derrota al entonces considerado mejor ejército del mundo. Sin embargo, la invasión francesa es consumada tiempo después, lo que obliga al presidente Juárez a retirarse al norte del país hasta Paso del Norte (hoy Ciudad Juárez), Chihuahua, e instaurar ahí la resistencia del gobierno liberal. Mientras tanto Napoleón III, apoyado por los conservadores mexicanos, trajeron a Maximiliano de Habsburgo, segundo heredero a la corona del Imperio AustroHúngaro a gobernar México en lo que se conoce como el Segundo Imperio Mexicano. Con la retirada de las tropas francesas de México debido a una inminente guerra entre Francia y Prusia y el fin de la guerra civil en Estados Unidos, los liberales se fortalecen y empiezan a avanzar al centro del país donde en Querétaro los esperan los conservadores al mando de Maximiliano, apoyado por Miramón, Márquez y Mejía. Después de una larga contienda triunfan los conservadores y se pone fin a la intervención francesa en México con el fusilamiento de Maximiliano de Habsburgo y los generales conservadores Miramón y Mejía al pie del Cerro de las Campanas el 19 de junio de 1867. El 27 de noviembre de 1867 el cadáver del emperador es llevado a Europa y el 15 de julio de ese mismo año el presidente Benito Juárez entra triunfante a la capital e inicia un periodo en el que el régimen 
republicano será la característica básica del país.

Conelascenso de Porfirio Díazala presidencia de México se enmarca una época de apogeo económico, pero también de grave explotación de las masas campesinas a partir de las haciendas que eran grandes extensiones de tierras en manos de unos cuantos ricos latifundistas que mantenían prácticamente muertos de hambre a los campesinos para amasar grandes riquezas. Estas haciendas, que afortunadamente ya no cumplen su tarea de explotación, han dejado lugares turísticos de gran atractivo. Ex haciendas como Temixco, en Morelos; San Miguel Regla, en Hidalgo; Acolman, en el Estado de México; e infinidad de haciendas que presentan tradición e identidad mexicanas. Asimismo, durante el Porfiriato se crearon algunos de los monumentos más importantes de la capital como el Palacio Legislativo, del cual irónicamente solo queda la cúpula del Monumento a la Revolución, el edificio central de correos de gran belleza artística, el Palacio de Bellas Artes construido por el italiano Adamo Boari y que pertenece a la llamada corriente de Art-Noveau (Arte nuevo) y el monumento del Ángel de la Independencia, obra del mexicano Rivas Mercado, que confirman a la capital como un punto histórico importante de visita del turista nacional y extranjero.

Durante el año 1908, ante el reportero norteamericano James Creel, el presidente Porfirio Díaz manifestó que los mexicanos ya estaban capacitados para gobernarse democráticamente, por lo que surgieron varios candidatos para la elección de 1910. El más fuerte de ellos fue Francisco I. Madero, quien de manera ilegal es encarcelado y aún en prisión participa en las elecciones que bajo fraude electoral Porfirio Díaz se declara vencedor. Madero logra escapar de la cárcel y huye a Estados Unidos, donde proclama el Plan de San Luis, que declaraba desconocer el gobierno del presidente Díaz, nombraba presidente provisional a Francisco I. Madero, condenaba el antirreelecionismo y llamaba a levantamiento armado al pueblo en general el 20 de noviembre de 1910.
Con el advenimiento de la Revolución Mexicana a partir del 20 de noviembre de 1910, el país sufre un cambio radical que llevará al México contemporáneo.

En el México contemporáneo la década de los años 60 del siglo pasado representa un cambio político-cultural importante que históricamente presenta a Tlatelolco como ícono de lucha y resistencia ante la represión gubernamental representada por los acontecimientos del 2 de octubre de 1968, donde una manifestación estudiantil fue injustamente reprimida pero que da significado a la lucha popular. Tlatelolco como punto histórico representa la confluencia de tres culturas: la prehispánica, la colonial y la moderna (Plaza de las Tres Culturas).

El recorrido turístico histórico puede ser interminable. Sin embargo, rara vez es aprovechado y en una economía que pretende crecer ante una inevitable extinción del petróleo, la historia y el turismo juntos son la llave del desarrollo.

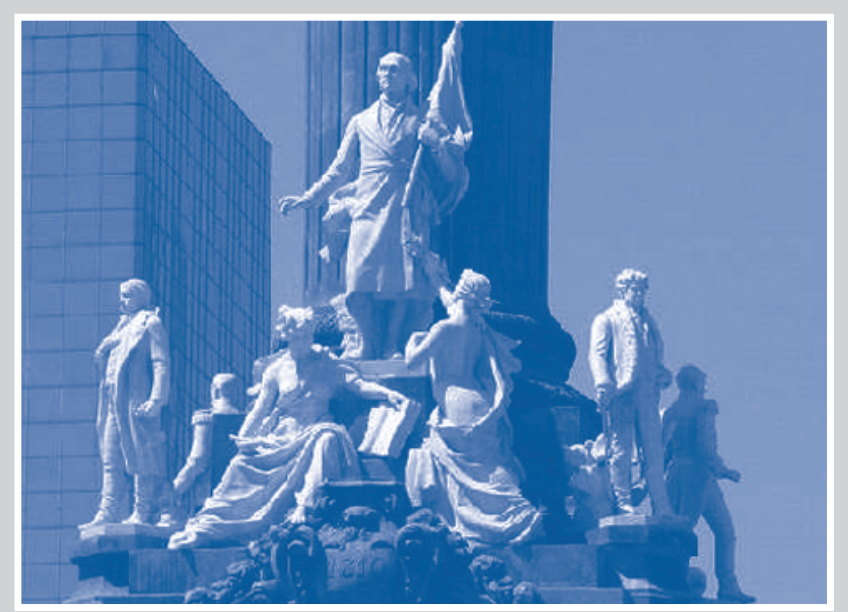

\section{Conclusiones}

México posee una riqueza histórica y cultural innegable, que es reconocida a nivel mundial, pero que no se ha sabido explotar con la magnitud necesaria para el desarrollo turístico del país y que abren una ventana al futuro a tener en cuenta por las presentes y futuras generaciones.

La historia de México representa una riqueza única y las huellas que ha dejado a lo largo del tiempo constituyen un patrimonio turístico importante que se debe valorar y fomentar en beneficio de todos. Turismo e historia representan una línea inseparable de conocimiento y potencial fuente de recursos ilimitados en espera de ser valorados y aprovechados. 